\title{
Totaleindruck o impresión total: La Telésfora de Aquinas Ried como proyecto politico, creación literario-musical, reflejo personal y encuentro con el otro.
}

\section{Totaleindruck or total impression. Aquinas Ried's Telésfora as a Political Project, a Literary and Musical Creation, a Personal Reflection and an Encounter with the Others.}

\author{
por \\ José Manuel Izquierdo König \\ Magister en Artes, mención Musicología \\ Facultad de Artes, Universidad de Chile, Chile \\ izquierdokonig@gmail.com
}

La Telésfora (1847), ópera en tres actos de Aquinas Ried, se ha instalado desde los trabajos de Eugenio Pereira Salas, como el primer drama lírico escrito en suelo chileno. El presente ensayo busca discutir esta consideración a partir del único elemento que le sobrevive: su libreto. A partir del mismo, la obra de Ried se revela como un proyecto político concreto, un reflejo personal de sus ideas y su encuentro con los chilenos, alemanes y mapuches de mediados del siglo XIX. En este sentido, la figura de Aquinas Ried se amplía a todo un espectro de la vida musical y cosmopolita de la ciudad de Valparaíso y los inmigrantes en Chile.

Palabras claves: ópera, romántico, inmigrante, mapuche, libreto, Ried

Telésfora (1847) is a three-act opera written by Aquinas Ried. Since the epoch of the Chilean music historian Eugenio Pereira Salas this work has been considered as the first lyrical drama composed in the Chilean territory after the independence. The following essay discusses this point in depth on the basis of the libretto, which is the only element of this opera that has remained. The libretto reveals a concrete political project as well as a personal reflection on Ried's ideas along with his encounter with Chileans, Germans and indigenous people of the nineteenth century. In this regard, the figure of Aquinas Ried reaches a wider spectrum encompassing the musical and cosmopolitan life of the city of Valparaiso and the immigrants in 19th-century Chile.

Key words: opera, Romanticism, immigrant, mapuche, libretto, Ried.

La Telésfora, de Aquinas Ried, ha sido referida en más de una ocasión como la primera "tentativa [...] para crear la ópera nacional, nacionalizada aún en su texto castellano". Pareciera que no existe en Chile noticia de una propuesta anterior, al menos 
bajo las actuales luces de nuestra historiografía. Sin embargo, esta aseveración nos plantea una serie de problemas, no tan sólo históricos, sino también teóricos. ¿Por qué habría de ser la ópera de un alemán, radicado en Chile sólo tres años antes de su creación, una obra efectivamente "chilena"? ¿Es sólo su fecha de composición y su temática, además de su texto, lo que nos lleva a considerarla en éstos términos? El siguiente ensayo busca una revisión de esta primera ópera chilena, mencionada frecuentemente, pero rara vez revisada, en gran medida, por el hecho circunstancial de que su música se ha perdido y de que la partitura, por razones ajenas al compositor, jamás fue estrenada. ${ }^{2}$

La creación de una ópera en Chile, por parte de un inmigrante alemán, no es un fenómeno que se pueda declarar, en primer término y sin discusión, como efectivamente chileno. Para ser considerada en estudio, se debe entablar un diálogo con los elementos que, pareciera, se conjugaron en su creación, en este caso, a mediados del siglo XIX. Aquinas Ried llega a Sudamérica por una serie de circunstancias que revisaremos más adelante, pero que pueden ser clasificadas de un modo amplio en lo que algunos historiadores han denominado la "Reisekultur" alemana, esto es, una inclinación histórica y cultural del pueblo alemán durante el siglo XIX para alejarse de sus fronteras, particularmente, como parte de la educación en la acomodada elite intelectual prusiana. Según el historiador Carlos Sanhueza, los "motivos económicos no bastan para explicar este fenómeno migratorio alemán, así como su interés en el viaje. Se ha buscado la respuesta para dicha característica en ciertos elementos culturales que habrían hecho propensa a su gente al traslado, como una suerte de 'criatura migratoria""'s.

Sin duda fueron los viajes de Alexander von Humboldt los que primero pusieron en el tapete a la América Hispana dentro de las expectativas de viaje de los jóvenes alemanes, cautivados anteriormente por el calor del Mediterráneo. En estos viajes el científico generó por primera vez su idea de un "cosmos", esto es, de un espacio universal inabarcable. Según esta teoría, el individuo es incapaz, desde su posición, de contemplar y experimentar la totalidad del mundo que le rodea. El viaje será aquel espacio móvil que le permita crear "die Welt im Kopf”, el mundo en la cabeza, atravesado por el arte, la ciencia y la literatura, las cuales pueden entrelazadas "confrontar dicha falencia experiencial en el pensamiento planetario". ${ }^{4}$ Es importante entender el fenómeno, por tanto, como uno interdisciplinario: la ciencia, de enorme utilidad en la descripción del universo, es incapaz, en la visión de Humboldt, de mostrar toda la experiencia vivida por el viajero. La intensidad de estos nuevos mundos no puede transmitirse sólo por la práctica científica, sino, esencialmente, por medios artísticos

${ }^{1}$ Pereira Salas 1957:243. Esta frase debe entenderse dentro de la noción tardo-decimonónica de la ópera como una forma de arte de mayor relevancia que otras formas similares de teatro cantado o música escenificada. Por tanto, ¿es de relevancia que no haya óperas anteriores, cuando sabemos de la existencia de escenas cantadas en Chile por lo menos desde el siglo XVII?

${ }^{2}$ Castillo 1998:35. Aquí se discute en una pregunta abierta hasta qué punto es relevante que la primera ópera chilena nunca fuera estrenada. Aunque este tema me parece esencial, en este ensayo busco discutir, justamente, el hecho de que La Telésfora haya sido la primera ópera chilena o hasta qué punto pueda llamársele chilena, un problema que, me parece, antecede a aquel planteado por Castillo.

${ }^{3}$ Sanhueza 2006:47.

${ }^{4}$ Sanhueza 2006:52. 
y literarios. A partir del arte se puede comenzar la búsqueda de una "impresión total" o "Totaleindruck" esencial.

La creación de la Telésfora de Aquinas Ried es, de alguna manera y a modo de hipótesis, un cumplimiento extremo de esta "impresión total" buscada por Humboldt, en la que las formas de arte que se entrecruzan en la ópera buscan generar una impresión completa sobre el espectador. Es así como se encuentran en la creación de Ried aspectos diversos de la cultura, sociedad, naturaleza e historia de un lugar determinado de estos "nuevos mundos". De alguna manera Ried llega incluso más lejos que los planteamientos naturalistas de Humboldt, encontrándose con el otro y asimilándolo como persona, más allá del universo de descripción científica. De igual y brillante manera lo haría el discípulo directo de Humboldt, el pintor Moritz Rugendas, en sus diversos trabajos sobre suelo chileno. Aunque según su maestro el cono sur era un lugar con poco que ofrecer, se decide a permanecer en nuestro país ocho años. En aquel intervalo, se aleja de la naturaleza, creando un amplio muestrario social de tipos humanos, expuestos en infinidad de páginas, más bien a la manera de un antropólogo que la de un naturalista.

La situación de Aquinas Ried, bastante distinta, se encuentra en los márgenes del marco común del alemán viajero, que ya he planteado. Llega a Chile en 1844. Sus orígenes, en primer término, nos son relativamente desconocidos. Según datos familiares, habría nacido en el castillo de Strahfels en Baviera, en 1810, aunque hay discusiones posteriores en cuanto al lugar y al año. No reconoce padres, quienes habrían fallecido durante las guerras napoleónicas. Sin embargo, tenemos algunas pistas sobre sus orígenes que son muy relevantes para un entendimiento de sus ideas en Chile. El castillo mencionado era en realidad, en aquellos años, un monasterio para refugiados escoceses católicos. Esto explicaría, por ejemplo, por qué cursó medicina en el Royal College of Surgeons de Londres, en el que fue reconocido con méritos como el doctor "James Aquinas Ried"s.

No quiero ser tautológico en volver a señalar que, el hecho que el autor de nuestra "primera ópera nacional" sea extranjero, es un factor vital para nuestras consideraciones, puesto que la idea de creación nacional, o de escuela artística por lo menos, se ve atacada por un nuevo flanco: ¿Hasta qué punto es chileno o, efectivamente, alemán, Aquinas Ried? Esta pregunta es esencial para determinar muchas de sus ideas políticas y artísticas posteriores. Al contrario de la figura calma y burguesa que nos presenta Pereira Salas en sus escritos, Ried fue un personaje extremadamente singular dentro del ya singular espectro de los primeros alemanes en tiempos republicanos de Chile, como los hermanos Philippi, Alexander Simon, Rugendas o el mismo Guillermo Frick.

En Inglaterra dejó Ried, al menos, a dos hermanas (Cate y Mary) y una prometedora carrera como médico bajo el auspicio de Lord Wellington. Por razones desconocidas, posiblemente políticas, se enroló como médico del ejército llegando a la desolada isla y colonia penal de Norfolk, la que llamará "el edén habitado por la escoria

\footnotetext{
${ }^{5}$ Información a partir de documentos familiares comentados amablemente por doña Ana María Ried de Undurraga, en parte, a partir de sus propias investigaciones familiares. Agradezco a ella sinceramente.
} 
de esta tierra". Allí estableció un sistema de enseñanza musical para reformar a los presidiarios el que, por su éxito, aún se recuerda en aquellos lugares. Sin embargo, su frustración era grande, acompañado sólo de una flauta y algunos libros. Trató de tomar el puesto de organista de Sydney, sin resultado. Buscó también maneras para que sus hermanas se instalaran en esas nuevas tierras. En Australia, además, Ried firmó siempre sus cartas como James A. Reid, y sólo podemos saber que, efectivamente, se trata de él, por las menciones que hace a proyectos que luego concretó en Chile, tales como la ópera Valkyria. Además, hay una manera similar de escribir que no puede ser desconocida. La historia de Ried en aquel otro sur del mundo, sin embargo, se detuvo por algunos problemas personales. Tras un romance y posterior "altercado" con la hija del gobernador, se embarca en un barco ballenero llegando a Valparaíso hacia 1844. Con todos estos altercados, es difícil pensar que en un par de años había completado ya una ópera. No obstante en sus cartas, Ried señala que ve a la Música (con mayúsculas siempre) como la única gran compañera, al escribir operetas para los conscriptos en su soledad. Así, no parece ilógico que este hombre, recién llegado a Chile, se propusiera estrenar una ópera completa, una que saliera del nivel intelectual de esa colonia para entrar de lleno al mundo del gran escenario o, al menos, el Teatro de la Victoria de Valparaíso. ${ }^{6}$

La situación musical en el puerto, en este sentido, parecía ser especialmente interesante para alguien como Ried. "No importa a la hora que uno pasee por las calles de Valparaíso, con seguridad se escuchará algo de música”, comentaba el viajero alemán Friedrich Gertstärcker durante su estadía en 1850. Aunque permaneció poco tiempo en la ciudad, su mirada es una de las más completas que tenemos de un extranjero sobre la vida musical y cultural en el puerto en tiempo de las composiciones de Ried. Sin duda, proporciona algunas luces sobre por qué Ried, luego de su estadía en la lejana isla de Norfolk, se decidió a componer y estrenar una ópera en suelo chileno. Así describe, justamente, el Teatro de la Victoria en el que debía estrenarse la Telésfora:

"es especialmente espacioso dentro de un edificio de muy respetable construcción. La orquesta en ese tiempo era excelente, y algunas óperas que escuché en aquel entonces me dieron una satisfacción perfecta. El primer tenor, particularmente, tenía una gran voz, y gozaba de gran popularidad. Además la actuación de las señoritas chilenas y caballeros era simple y del todo natural".

Al salir del teatro por primera vez, se sorprendió mucho al escuchar venir, desde los muelles "música alemana", justamente la obertura de la ópera Martha de Flotow interpretada por una banda. ${ }^{7}$

Ried, sin embargo, no tenía la misma impresión de la vida musical en la ciudad. "Este pueblo sin embargo no es para los artistas - es reducida la población y ocupada en el comercio, y no existen por acá grandes familias de señoritas, que se ocupan de

${ }^{6} \mathrm{La}$ información de este párrafo se basa en las cartas escritas por Ried a sus amigos y que se encuentran en Australia. Fueron fotocopiadas y traídas a Chile por el doctor Bryan Gandevia de Sydney, con ocasión de un congreso médico en nuestra capital.

Gerstärcker 1854:123-124. Traducción propia. 
la música." Profundizando un poco años más tarde, en referencia a su última ópera, Diana, señala lo siguiente:

"Los coros son pesimos aquí - pero les he exigido mui poco en esta composición, y con la addicion de un bajo o dos se podria vencer esto. El tropiezo principal en la actual compañía es el director de la orquesta - Escalante, una nulidad completa en cuanto a conocimientos musicales, y un estorbo en la orquesta tal, que los primeros artistas del mundo no podrian seguir con semejante direccion. Pero mientras que su señora forma parte de la compañía sera difícil deshacerse de él".

En una carta del 22 de octubre de 1868 a la misma Isidora amplía su comentario. "Lo único que me da desconsuelo es el director de orquesta - pues es el mayor chambón que he visto, aun aquí - y esto quiere decir mucho.” De alguna manera, esto me lleva a pensar que la composición, para Ried, era antes un acto de esperanza y expresión que una actividad práctica en la vida musical de su propia época. Incluso, podría pensarse que el texto de La Telésfora, o más bien su contenido simbólico, venía trabajándose desde tiempos muy anteriores, quizás previos a su llegada a Chile. Sobre esto profundizaré más adelante.

La historia del estreno puede describirse rápidamente. Ried, entusiasmado con la voz y los talentos de la compañía Pantanelli, de la capital, decide montar su trabajo ya a fines de 1846. Sin embargo, 10 días antes del estreno en 1847, la protagonista y los músicos regresan sin aviso y sorpresivamente de vuelta a Santiago. Ried, frustrado, cancela el anunciado estreno. Toma dos días más tarde un coche junto a su esposa, camino a Sucre, donde había sido invitado por el presidente de Bolivia a fundar la Escuela de Medicina de la nueva Universidad. Sin embargo, esta tentativa fracasa meses más tarde por razones políticas, debiendo volver Aquinas a tierras chilenas. ${ }^{10}$ Sabemos por su diario de viaje al sur, redactado durante el verano de 1847 que la planificación del estreno demoró casi un año. En él señala que está muy interesado por el estreno de esta ópera, que espera se realice pronto. Confiado en su calidad musical, deja además algunas copias en el camino para que sean interpretadas en Concepción ${ }^{11}$. También le dejará un par de coros de la misma a Guillermo Frick en Valdivia quien, aparte de cantarlos con el autor al piano, no vuelve a interpretarlos. ${ }^{12}$

El Mercurio de Valparaíso, poco antes del estreno, había impreso públicamente el libreto y realizado amplia propaganda, incluso enviando a un periodista a los ensayos para comentar sobre la calidad de la obra. Es esta impresión del libreto de la Telesfóra nuestra mejor referencia a las verdaderas intenciones de Aquinas Ried, y un elemento

\footnotetext{
${ }^{8}$ Carta del 14 de octubre de 1856 a Isidora Zegers.

${ }^{9}$ Carta del 8 de octubre de 1868 , a Isidora Zegers.

${ }^{10}$ El 27 de diciembre de 1847 pierde la presidencia José Ballivián, quien mandó llamar a Ried.

${ }^{11}$ Para la revisión de este diario, utilizamos la copia publicada de manera familiar por Ana María Ried, que nos parece la más autorizada traducción del texto, incompleto desde su versión original.

${ }^{12}$ Cartas de Guillermo Frick a Franz Fonck y Hugo Kunz en el archivo Emilio Held Winkler. Señala que, aunque tenía en su poder algunas cosas de Ried, no las estrenó públicamente, pero sí cantaba frecuentemente con su coro la "Canción a la Novara", única composición de Aquinas Ried existente en nuestro días.
} 
esencial para mi ensayo y comprensión del autor y la obra. Para la historiografía tradicional la ausencia de música era razón suficiente para no estudiar este texto, debido a un error particular de Eugenio Pereira Salas y Samuel Claro, quienes no consideraron el texto como un material importante de análisis. De este modo, llegaron a conclusiones muy parciales. Me parece ésta una razón suficiente para sí revisar el libreto con criterios más amplios respecto a su contenido y a la figura e ideas de Ried en su propio lugar y tiempo.

"La primera ópera escrita en el territorio chileno resultó ser la de este médico alemán", señalaba Samuel Claro. ${ }^{13}$ Ópera, sin duda, escrita en castellano, con música "alemana". ¿Se puede hablar de música alemana? No entraré en este tema desde una perspectiva estilística, pero sí me parece que es importante pensar en la influencia de Weber, en cuanto al modelo para Ried al generar una ópera nacional. Carl Maria von Weber logró, quizás más que otros autores, la conciencia no de una ópera alemana, sino que de la necesidad de la misma. La búsqueda de "lo nacional" iba más bien por cuestiones de idioma y un uso del lenguaje e imágenes comunes, más que por una revolución musical. Esa será una búsqueda que, si bien comienza con Euryanthe, sólo se profundiza desde una perspectiva teórica con Richard Wagner, en épocas posteriores al trabajo de Ried. ${ }^{14}$ La búsqueda de motivos comunes a la nación completa, el rescate de ideas simbólicas, y la unión de la música mediante algunas escenas de carácter referencial, son esenciales para el movimiento temprano de la ópera romántica nacionalista y revolucionaria, como es el caso de Meyerbeer y Spontini.

Rara vez se busca una idea de escritura musical "alemana”. Lo más marcadamente alemán de Weber, sin duda, son algunos recursos de tono folclórico, particularmente en la gestualidad y el timbre. Los casos más obvios son los coros de cazadores de Freischütz y Euryanthe. Aunque no conocemos la partitura de la Telésfora, ésta en su libreto incluye algunas anotaciones relevantes que pueden apuntarnos nuevamente a la influencia de Weber. En primer lugar, Aquinas Ried hace uso en algunas ocasiones de imaginativos recitativos con guitarra y, de modo increíble para la época, el tercer acto comienza de manera única con el uso de "Araukobläser", o bronces de Arauco probablemente trutrucas que anuncian la batalla por venir. La idea de usar este instrumento pudo haber nacido durante su viaje al sur, en el que incluso realizó un pequeño dibujo esquemático del mismo: ¿Pensaría en cómo escenificarlo?

Poco más sabemos de las orquestaciones de Ried. Hasta cierto punto, las descripciones que hizo sobre su ópera Diana, vertidas en cartas a Isidora Zegers, pueden sernos útiles para entender un acercamiento práctico -casi pragmático- a la composición, que toma siempre en cuenta los medios disponibles. El 8 de octubre de 1868 le escribe señalando lo siguiente: "tengo instrumentado el primer acto - empleando solamente los instrumentos que se encuentran en nuestra pobre orquesta". Pocas semanas más tardes amplía su comentario:

"En cuanto a los recitados, he tratado de condensarlos a lo casi indispensable, omitiendo todo dialogo 'parlante', y creo que no se necesitará mas que

\footnotetext{
${ }^{13}$ Claro 1973:103.

${ }^{14}$ Meyer 2003:5-6 y 41.
} 
una regular capacidad, y poco de estudio para vencer este obstáculo (...) Los coros son sencillos y la orquestación calculada para los elementos que tenemos aquí". ${ }^{15}$

Sin embargo, es interesante contrastar este punto con una carta anterior, del 8 de octubre del mismo año. En ella, Ried señala lo siguiente: "Como mi primer ensayo fracasó, en las dificultades del conjunto y de la orquesta, me propuse escribir una opera mas facil, y que se pudiera representar con los elementos que aquí se encuentran." Diana, por lo tanto, fue pensada como un contraste a Telésfora, como una manera de superar sus defectos. Esto nos lleva a pensar que esta primera ópera nacional contenía "diálogos parlantes", que pudieron verse enfrentados al italiano materno de muchos de los cantantes (un asunto que Ried discute con Zegers en la misma carta). Además, puede que la orquestación haya sido realizada de manera más compleja y con una orquesta más amplia, según algún modelo de Mozart, Haydn o Weber. Sin embargo, esto no lo sabemos. Sólo podemos quedarnos con lo que sí es Diana en términos instrumentales, a partir de estos comentarios. Sobre la calidad musical de la obra de Ried, en términos generales, sólo tenemos el comentario de Guillermo Frick. Al participar Frick con una obra en la Exposición de Artes e Industrias de 1872, señala hacerlo sólo porque Ried, su "verdadero competidor en el arte musical", ya había fallecido. Con esto deja entrever que lo consideraba ampliamente como un mejor compositor. $^{16}$

Uno de los temas fundamentales al acercarnos a la obra, real o imaginada, de Aquinas Ried, es su condición de alemana o chilena. La idea de una "música alemana", como música chilena, es un problema puntual si se toma en consideración la única obra que sobrevivió a Aquinas Ried, su Canción a la Novara. La misma está escrita en el estilo de los corales masculinos que podemos encontrar en Weber o Schubert, veinte años antes de la llegada de Ried a Chile. Dicho estilo sería parte esencial del mundo masculino alemán en Chile durante el siglo XIX, según podemos apreciar en los libros de canto que han sobrevivido de aquella época y que se encuentran en el Archivo Emilio Held Winkler. ${ }^{17}$ Esta idea de lo alemán en cuanto a expresión musical natural de los emigrantes, es especialmente interesante, puesto que es generada como una antítesis de Inglaterra, Francia e Italia, naciones en competencia con Alemania en aquella época. La música chilena, para estos alemanes, sería por tanto, aquella que se aleja del sonido italiano reinante en el país a mediados del siglo XIX.

Para Guillermo Frick, compositor y amigo de Aquinas Ried, la música en tiempos de su llegada a la ciudad de Valdivia, era sólo la de guitarra y las melodías italianas ${ }^{18}$. Por lo tanto, sus composiciones eran las primeras creadas en ese territorio que podían llamarse, en su opinión, como "música valdiviana" al alejarse de influencia italiana. Ried toma una postura bastante similar, aunque no rechaza a los grandes belcantistas

\footnotetext{
${ }^{15}$ Carta del 5 de noviembre de 1868.

${ }^{16}$ Izquierdo, 2008:34. El comentario se encuentra en el segundo volumen de la Valdivianische Musik. de Frick.

${ }^{17}$ Pereira Salas 1941:139. Los libros fueron consultados gracias a la gentileza de Christine Gleisner el año 2007. La partitura de la Canción a la Novara la encontré, gracias a una sospecha de Ana María Ried, en la Biblioteca Nacional. ${ }^{18}$ Prólogos al primer y tercer tomo de su Valdivianische Musik, Valdivia, 1899 y 1905.
} 
italianos. De alguna manera, lo chileno sólo podía entenderse como tal en la medida en que se refiriera a lo propio, esto es -en el caso de ambos compositores- como lo alemán.

La Telésfora, u “Ópera Heroica en Tres Actos”, según reza la portada del libreto impreso, está estructurada en torno a un curioso episodio de la independencia, utilizado de forma simbólica por el autor. Seis son los personajes principales de la ópera: Pelayo (patriota), Gonzalvo (realista, luego patriota) y Lincoyán (cacique mapuche); luego Auca (el hijo pequeño de éste último, pero actuado por una mujer), Telésfora (viuda y cuñada de Pelayo) e Irene (su hija y amor de Gonzalvo). A vuelo de pájaro se aprecia una clara estructura de tres hombres y tres mujeres (si consideramos como mujer al niño), estructura que define la trama simbólica de la obra entera. En los tres hombres se ve claramente la representación de los tres niveles que Ried considera propiamente chilenos: el criollo campesino, el español "convertido" por la causa de la libertad y el mapuche "siempre libre".

El personaje de Lincoyán es esencial para el desarrollo de la ópera y su comprensión simbólica, dentro del pensamiento de Aquinas Ried, puesto que el indígena, el mapuche, es la alteridad esencial para el alemán en tierra chilena, un otro que puede ser parte del "yo" en esta nueva tierra americana. Sin embargo, una primera gran sorpresa es que, en sus Orígenes del arte musical en Chile, Pereira Salas ni siquiera menciona a este personaje en el elenco de la trama. Más relevante aun para nuestro análisis resulta ser que en una descripción resumida de toda la trama el personaje es omitido deliberadamente, con el agregado del comentario de otro autor, según el cual Ried no habría caído "en la vulgaridad de personificar a la América en una india"19. No se trata, sin embargo, de un desprecio hacia el indígena, propio de nuestras elites nacionales o de la idea de progreso musical que Pereira Salas seguramente otorga a la primera ópera nacional (o al menos no pareciera así). Pero sí se advierte la falta de profundidad en las ideas de Ried como creador, inmigrante e intelectual. El asunto es algo más intrincado y enfoca una serie de problemas vitales para la época, entre ellos, el choque de extranjeros (en particular alemanes), con los chilenos y mapuches dispuestos sobre un mismo territorio.

Para el chileno, y según principios eminentemente franceses, el estado-nación decimonónico se articula de tal manera, que es el primero el que construye el segundo, esto es, que las leyes y demarcaciones territoriales son las que producen, finalmente, una cultura unitaria. Para el chileno, la nación es, finalmente, "lo que unos imaginan -aunque luego lo lleven a la práctica gubernamental- [donde se] pone un énfasis en el papel primordial de los grupos elitarios. Ellos se constituyen en el actor principal de las naciones a partir de su voluntad constructivista". ${ }^{20}$ Sin embargo, el imperio alemán, por los mismos años, se conformaba bajo la idea igualmente arbitraria, pero radicalmente opuesta, de que la suma cultural de su gente es la que crea, identitariamente, una nación, y el estado es solo una construcción sobre ésta. Por lo tanto, se construye también la premisa exógena de que cada cultura expresa elementos únicos que la diferencian respecto a otras. Sin embargo, para el alemán que llega a Chile, las

\footnotetext{
${ }^{19}$ Pereira, 1941:136, citando a Roberto Hernández.

${ }^{20}$ Sanhueza 2006:32,101. Esta tesis ha sido más bien explorada por el historiador Gabriel Salazar.
} 
ciudades centrales se presentan más bien como una pobre copia de ideales europeos, implantados sin gran cuidado ni verosimilitud.

En contraste, el indígena, en particular el mapuche, es para el alemán un ser "en estado natural", "indios no contaminados por la influencia externa, como tampoco por un sistema político que los hubiese obligado a transformarse". ${ }^{21}$ Para los alemanes, la Araucanía -como bien lo señala Guillermo Frick en su prólogo a Orélie Antoine - es la "Freie araukanische Grenze" (Frontera Libre Araucana) y, por lo tanto, una tierra -en palabras del viajero Paul Treutler- de "indios araucanos, salvajes e independientes" ${ }^{22}$ Así, el viajero romántico alemán encuentra rápidamente en la causa mapuche, que se comenzaba a gestar en aquellos años, un punto en común, un espejo a esos socialismos utópicos de la generación de 1848 y los ideales románticos de una humanidad ligada a la naturaleza e inocente desde su esencia, profunda y contradictoriamente burguesa. Es en esos ideales en que se gesta el drama de La Telésfora.

Una serie de elementos, mitad sugestionados mitad verosímiles, apoyan para el alemán idealista, el inmigrante aventurero (no tanto para el colono), esta idea de que el chileno es el verdadero enemigo, y el mapuche es un hombre que lucha por sus derechos. Si bien, según todas las crónicas americanas, los "indios" esperados debían ser esencialmente morenos, parecían a ojos alemanes más blancos que los "chilenos" de la zona central. Guillermo Frick algo señala nuevamente en sus apuntes para Orélie Antoine. Allí relata cómo Aquinas Ried, tras su primer viaje a través de la Araucanía, llega a Valdivia y se aloja donde su amigo y colega. Cuenta Frick, que Ried "en una conversación con mi familia se expresó con tanta alabanza sobre el físico de los indígenas, que dijo: 'parecen alemanes"”23. Además la moral del mapuche les parecía mucho más cercana a sí mismos que a los chilenos de la zona central. Si bien se emborrachaban tanto o más que éstos, jamás terminaban sus veladas en peleas o actos "inmorales o insolentes" de ningún tipo. Aunque había poligamia, no se veía ni promiscuidad ni libertinaje. El adulterio y la seducción excesiva eran castigados con la pena de muerte. En la imagen creada por estos alemanes, los indígenas eran por lo general más aseados, se cambiaban más sus prendas de vestir y en general eran mucho más pudorosos que los chilenos de la zona central: "Aquí, el indio chileno se constituía en una suerte de espejo que les reflejaba su propio lugar, su mundo". ${ }^{24}$

Además, el mapuche representaba para el alemán la unión de dos conceptos esenciales para la mirada romántica del mundo, esto es, la simbiosis entre la perfección pre-adámica y el universo natural que nos rodea. Observemos esto en un retorno necesario al libreto de la Telésfora. En primer lugar (y dentro del proyecto de "impresión total") la naturaleza es parte esencial de la mayoría de las indicaciones de decorado y éstas, lejos de funcionar de manera estática, tienen una relación profunda con el interior de los personajes e, incluso, con el desarrollo de importantes ideas simbólicas de la trama. Pelayo, por ejemplo, sólo es convencido de volver a tomar su sable y luchar por la libertad al contemplar la cordillera nevada. Por contraste las voces de las mujeres no lograron ningún efecto en tal sentido. Gonzalvo sólo entiende

\footnotetext{
${ }^{21}$ Sanhueza 2006:227.

${ }^{22}$ Treutler (1882) 1953:18 (Prólogo a la edición de su Diario de viaje).

${ }^{23}$ Frick, apuntes para una presentación de Orélie Antoine I, Museo Histórico Universidad Austral de Chile.

${ }^{24}$ Sanhueza 2006:232.
} 
a su amada cuando ésta compara su amor con la naturaleza. Lincoyán decide que toda la guerra tiene sentido, si sus bosques logran así permanecer libres, para el disfrute de las nuevas generaciones.

Los elementos simbólicos, de cierta sublimidad en el sentido kantiano, son abundantes en la obra de Ried, incluso a un nivel "cotidiano". Tal es el caso del Himno de la Segunda Compañía de Bomberos de Valparaíso (de su autoría en texto y música) el que cierra con las siguientes palabras: "Fuego es aquel elemento, a través del cual el oro se revela; donde brilla y donde quema, ahí está el valor del hombre". ${ }^{25}$ En varias descripciones aparece, poéticamente, una estrella en el cielo, como al comienzo mismo del primer acto: "Paisaje silvestre, con estensa vista de una bahia. A la izquierda la entrada de la caverna. En el firmamento relumbra el lucero. En la distancia una montaña nevada. Oscuro." Este tipo de descripciones, junto con aportar un tono psicológico y atmosférico, son esenciales a la trama. Finalmente, será Telésfora quien tome esta estrella y la instale en la bandera en el acto final del libreto, en una escena que no deja de recordarnos a "La libertad guiando al pueblo" de Delacroix. Con este gesto, el pueblo entero comienza a cantar el himno nacional: "Ciudadanos, el amor sagrado..." La música y las ideas de Ried se funden con dos emblemas incuestionables para el chileno "culto" de raigambre cosmopolita y el europeo de Valparaíso, esto es, el público objetivo de Telésfora. Mediante estos elementos fuertemente simbólicos, casi diría que descaradamente denotados, Ried retoma principios de compositores germanos de su época. Según los planteamientos de Weber y Wagner, la ópera alemana no pasaba tanto por problemas técnicos o morales de diferenciación con otras óperas de otras naciones, sino por "cómo los conceptos estéticos y éticos eran combinados en la generación de un nuevo sentido de identidad nacional alemana". ${ }^{26}$

Un tema que podemos reconocer mediante esta última escena, y la tripartición del elenco del libreto, es el rol de la mujer en esta nueva sociedad republicana. Sin duda, aquí Ried se nos muestra mucho más retrógrado que liberal. No obstante debe entenderse que la liberación del rol femenino será un proceso más bien de décadas posteriores en la revolución burguesa europea. La mujer sólo ocupa un rol en esta ópera en la medida que mueve al hombre a tomar acciones. Únicamente el gesto final de Telésfora tiene un trasfondo activo, pero que aún así es sólo el de concretar un gesto que ya ha sido generado por contraposición de fuerzas masculinas. En una carta a Isidora Zegers, Ried se expresa con claridad sobre el tema, en referencia a los intentos de la compositora por formar una Sociedad de Conciertos en la capital.

"En cuanto al reglamento de la Sociedad - me parece que les sería enteramente inutil. Lo que se necesita para reuniones de esta clase, no son reglamentos, sino entusiasmo y un centro, un resorte que comunique su impulso a la mayoria. No teniendo estos dos elementos, ninguna sociedad podrá existir como tal. Ud. hará mucho, pero faltará la fibra masculina - faltara el respeto que esta clase de jente involuntariamente prestan al hombre, y que

${ }^{25}$ Fonck ca 1900:67.

${ }^{26}$ Meyer 2003:7 "ethical and aesthetic concepts were combined in a new sense of German national identity". 
para una mujer será casi imposible que les arranque el respeto debido. El error de Santiago, y de los santiguinos en jeneral es que pierden su tiempo en arreglos, y leies, y ordenanzas - sin llegar nunca a ponerlos en obra”. ${ }^{27}$

Otro aspecto fundamental en Telésfora, es el fenómeno de la "divinidad" de la naturaleza, de sus profundas propiedades místicas y el poder frente a su contemplación, todo lo cual es un continuo del arte romántico que se aprecia tanto en Beethoven como en Friedrich, en Goethe, Byron o Berlioz. Este continuo subyace en muchas de las iniciativas de estos primeros alemanes en Chile, quienes llegaron como exploradores, aventureros, y se asentaron extasiados en la contemplación de la naturaleza. El bosque chileno es esencial al arte de los mismos, en cualquiera de sus formas. Guillermo Frick le canta a los árboles en varias de sus obras, y Alexander Simon pinta el Lago Ranco como si de una acuarela minimalista asiática se tratara. Los árboles de la selva valdiviana se transforman en estudios, de colores, de formas, de expresiones personales que, como en la pintura de Friedrich y Turner, son a la vez reflejo del artista mismo. ${ }^{28}$ Ried, en su "Germanische Wanderlieder", o "Canción alemana del caminante", señala así (en traducción propia): "Ese es el Abc de la sabiduría, su texto -libro de libros-, la naturaleza". ${ }^{29}$ En "Im Urwald von Arauco" o "En lo profundo del bosque de Arauco" (1847), ${ }^{30}$ Ried declara aún más puntualmente el lugar de la naturaleza en la experiencia humana: "El bosque mi cuna, el bosque mi escuela, mi sueño, mi esperar; mi todo es el bosque". ${ }^{31}$ Otros poemas similares pueden encontrarse en su diario de viaje, redactados en inglés. En éstos y otros, se ve claramente uno de los pilares esenciales en el discurso de la Telésfora. Es el bosque y la naturaleza chilenas, ese segundo Edén (luego de Norfolk), el que transforma al español en chileno, al criollo en patriota y es el espíritu de esa pureza natural la que le da al mapuche sus valores. "Por su carácter -dice Ried en su diario de viaje-, los araucanos son de un valor indómito, pero generosos; astutos, distínguense por un amor irreductible por su libertad", como señala en su diario de viaje.

Para Ried, el mapuche es el ejemplo perfecto de un habitar la naturaleza que no puede entenderse si no es en una profunda relación con la noción de libertad. Como canta Pelayo al final de la segunda escena del primer acto: " $i$ Triste sepulcro el mundo sería, quitado del cielo el sol libertad!" Aquinas Ried, en su diario, escrito en el lugar mismo donde germinó esta idea del indígena, no puede ponerlo de manera más clara:

"Vosotros les enseñáis los misterios de vuestra religión, los bautizáis, los obligáis a repetir mecánicamente el Credo y el Ave María, pero vosotros

\footnotetext{
${ }^{27}$ Carta del 11 de diciembre de 1852 a Isidora Zegers. El destacado es de Ried.

${ }^{28}$ Sobre este punto, en Estados Unidos es muy valorada este tipo de pintura, llamada a veces "místico simbólica" o, más genéricamente, de la "escuela de Hudson", que fue un paisajismo muy personal, contemplativo y majestuoso realizado en gran medida por emigrantes centroeuropeos.

29 "Das ist das Abc der Weisheit nur,/ ihr Text -das Buch der Bücher-, die Natur". En este caso, el abc es la contemplación que ha manifestado durante todo el poema.

${ }^{30}$ Aquí "Urwald", connota tanto bosque profundo como bosque primigenio u original (en el sentido de nativo y también de raíz esencial).

${ }^{31}$ Traducción propia: "Der Wald meine Wiege, der Wald meine Schule/, mein Träumen, mein Hoffnen, mein alles der Wald".
} 
también les arrebatáis sus tierras y los engañáis en las compraventas. ¡Vosotros seducís a sus esposas e hijas, tratáis al indígena como se trata a los perros, no les enseñáis ningún principio útil y a fuerza de todo, después os asombráis que persista en su fiereza y en su obstinación, y que guarden un odio y un desprecio implacable contra todos los blancos!"

Si bien la actitud paternalista es clara, en cuanto al planteamiento de dos sociedades opuestas por sus niveles de desarrollo, de igual manera se declara la libertad en conjunto con una asimilación. Aquinas Ried toma parte por el mapuche en una guerra que se está iniciando por ocupar los territorios de la frontera. En el libro La reindianización de América, siglo XIX de Marta Irurozqui y Leticia Reina, la figura de Aquinas Ried (más allá de la música y las artes) tiene un lugar central en los discursos proindigenistas de comienzos de la república.

"Enemigo del empleo de la fuerza, descubrió, con mucha claridad, los motivos por los cuales los españoles no habían doblegado al mapuche: la falta de incentivos materiales que justificaran su conquista. (...) 'En Chile hay un millón y medio de habitantes, pudiendo vivir diez, ¿Para qué, entonces, conquistar Arauco? (...) Las monedas chilenas dicen Por la Razón o la Fuerza, aludiendo a los fundamentos de la Independencia. ¿No tendrá acaso el araucano el mismo derecho a invocar este principio para defender su libertad?' (...) Ried era partidario de una colonización que respetara los derechos del indígena e indemnizara a quienes quisieran vender sus tierras. Sus opiniones tienen el mérito de constituir las primeras manifestaciones de un proindigenismo que se gesta en oposición al antiindigenismo de quienes promovían la ocupación de la Araucanía sin reparar en los medios a emplear." 32

Un somero análisis de las opiniones vertidas por Ried en distintas fuentes y durante un transcurso de varios años nos aclara la relevancia que tiene para él el problema indígena. De aquí la figura de Lincoyán, que pelea en la trama de la ópera por su propia libertad, y no la de toda la nación. Es él quien protege sus tierras, sus bosques y su dignidad. Se podría incluso decir que él es la figura, en su momento, más actual y polémica de toda la trama. Hasta cierto punto sigue siéndolo. No puede compararse con los ideales teatrales de un viejo que vuelve a luchar y de un joven enamorado por una mujer y una causa, puesto que ambos son personajes que podríamos encontrar sin problemas en otras óperas de la época, ya sea bajo motivos italianos, alemanes o franceses.

Sin duda, no era la primera vez que el problema mapuche era homologado a las causas libertarias. Ya había sucedido en tiempos de la independencia chilena. En la Logia Lautaro y periódicos como Cartas pehuenches, la idea de incorporar la lucha indígena a la causa antiespañola parecía casi lógica. "Surgió así, un sentimiento de

${ }^{32}$ Irurozqui, et al; 1997:144-145, citando un artículo de Aquinas Ried en El Mercurio de Valparaíso, de 1860. 
respeto y admiración hacia los mapuche, quienes son incluidos en el discurso patriótico como los altivos luchadores por la libertad y es elocuente que para la fiesta del primer aniversario del 18 de septiembre, las damas asistieran al baile de gala celebrado en el palacio de gobierno vestidas de 'indias"'. ${ }^{33}$ Esto terminó, previsiblemente, cuando los mapuches entendieron que "los españoles reconocían el territorio y la autonomía del Pueblo Mapuche, en cambio los patriotas pensaban en un territorio unificado bajo la bandera chilena desde el norte hasta el Cabo de Hornos." ${ }^{\prime 34}$

En este sentido, creo que el indígena representado por Ried en la Telésfora guarda diferencias claves con ese sujeto referido por la elite santiaguina en tiempos de independencia, en particular por ser vivenciado de manera directa. Sin duda, Ried llevó prejuicios de diverso tipo -en un grado no menor evolucionistas- a su encuentro con la frontera del sur, pero fueron prejuicios distintos al del habitante del Chile central, en particular el urbano. La validación del indígena, en la clase alta capitalina, es la de un sujeto del pasado, sin relación con "los indios de carne y hueso, coetáneos a ellos. Estos últimos fueron vistos como una copia defectuosa de sus predecesores (por su degradación moral, atribuida al alcohol) y como un obstáculo al progreso de la nación". ${ }^{35}$

La radical diferencia de Ried, y la omisión por parte de Pereira Salas, puede atribuirse a que aquel "indio" de la Telésfora, es generado a partir de su propio tiempo, validado en tiempos republicanos, y convertido en un eje central de la nación emergente junto al mestizo y el español "convertido". Así, aunque el discurso de Ried no es revolucionario en el sentido de que otorgue un planteamiento novedoso o único, sí lo es por su contemporaneidad y por nacer de una propulsión de intereses distinta, que de alguna manera forcejea con esa inclusión nacional del indígena propuesta en tiempos de la independencia. Así, la asimilación libre del indígena y la libertad retoma fuerza en tiempos en que, sin duda, tal discurso ya se había apagado o cambiado de rumbo en alas del progreso. En un artículo que, declaradamente, nació de reflexiones comunes con Aquinas Ried, Guillermo Frick escribió: "Antonie Orelie no tiene por qué avergonzarse de sus súbditos". ${ }^{36}$ Creo que no hay mejor manera de resumir la postura de Ried.

Pero el caso de Lincoyán, aunque central, es también parte de un cruce, una relación de intereses entre los tres protagonistas masculinos (y, por derivación, a los femeninos) del libreto, siendo un móvil común la libertad y la lucha por ésta. Las diversas arias y, en particular, los tercetos y otras escenas de grupo nos remiten rápidamente al sueño humanista de obras más famosas tales como la Flauta mágica de Mozart, Fidelio de Beethoven o, el referente más cercano, el Cazador furtivo, de Weber. Tal como lo señala Stephen Meyer, esta última "tuvo una importante influencia no solo en la historia del estilo operático, sino también en la historia de la recepción

\footnotetext{
33 Aylwin et al 2008: 346.

${ }^{34}$ Aylwin et al 2008:349.

${ }^{35}$ Pinto y Salazar 1999:140

${ }^{36}$ Frick, Apuntes para una presentación de Antonie Orelie, copia en una colección personal del autor. El original manuscrito se encuentra em el Museo Histórico y Antropológico Mauricio van de Maele de
} Valdivia. 
de la ópera. Ayudó a cambiar ideas fundamentales acerca de la relación ente este género y la sociedad y el rol de la ópera en la creación de una identidad nacional" 37 .

De hecho, al igual que en Weber, la idea de lo nacional es secundaria a los valores que están enraizados en esa idea de lo nacional. El leitmotiv esencial de Telésfora no es la chilenidad, la independencia o cualquier otra apropiación histórica o cultural similar, se trata más bien de la impresión de libertad que tiene un alemán cercano a la revolución republicana de 1848 en un país que él siente como esencialmente libre, pero que pronto se dará cuenta que no lo es. Es este concepto abstracto, pero muy firmemente arraigado, de libertad, el que transforma a los personajes en meras excusas de un ideal, o en propios ideales humanizados.

No será, y esto es muy importante, la última vez que Ried hará algo semejante. En 1846, año de la Telésfora, comenzará a escribir la que considerará la más importante entre todas sus obras, Teutonia, un drama (hablado) en tres actos con evidentes similitudes a la ópera. ${ }^{38}$ Sin embargo, este anverso alemán será trabajado durante más de una década, en buena parte producto de los intentos por una unificación cultural alemana, ideal que despierta gran cantidad de líneas poéticas a la pluma de Ried. Así, por ejemplo, un marino en ultramar debe encontrarse con su propia identidad alemana alejado de su patria. Puede hacerlo sólo en la medida en que en el mar puede cantar a todo pulmón sobre su propia libertad. La comparación con el personaje de Pelayo es clarísima, cuando éste en el fondo de una caverna replantea su chilenidad a partir de la naturaleza de la Cordillera y sus propios sentimientos de libertad.

Similares personajes se encuentran en sus poemas épicos, diversos dramas (tales como La tempestad) y, naturalmente, en sus otras óperas inconclusas. En particular tenemos noticias del tema de la libertad específicamente tratado en Il Granatiere, Walhalla y Diana. En el caso de esta última, según Pereira Salas, la obertura "debía tocarse con mucha pretensión pues era el leitmotiv que caracterizaba el tema de la libertad, simbolizado en el General Alfanje". Según el mismo autor, en el Certamen Internacional de Música del Teatro Municipal de Santiago, en 1894 (varios años después de la muerte del compositor), la misma obertura habría conseguido el Premio de Honor. ${ }^{39}$ Ried, al final de su vida y por lo que podemos observar en sus cartas a Isidora Zegers, tenía más expectativas de montar Diana que Grenatiere basada en los últimos 100 días de la vida de Napoleón. Al respecto señala, "Tengo un vivo deseo de ver a mi 'Grenatiere' en escena pero habría que cortar y destrozar mucho, pues la composición aspira a ser de Grande Opera, con coros dobles y trozos complicados de conjunto. Pero ya veo, que para poder hacer verlo, tendré que hacer sacrificios (...) En fin, con paciencia se gana el cielo, al menos el purgatorio, y la paciencia no falta." 40

Lamentablemente, la música de Aquinas Ried que no fue consumida por el bombardeo a Valparaíso de 1866, lo fue durante otros incendios y terremotos, al punto que

\footnotetext{
${ }^{37}$ Meyer 2003:4. Esta ópera "had an important influence not only on the history of operatic style, but also on the history of opera reception, helping to change fundamental ideas about the connection between opera and society and the role of opera in the creation of national identity".

${ }^{38}$ Fonck ca 1900.

${ }^{39}$ Pereira Salas 1941:139.

${ }^{40}$ Carta del 25 de noviembre de 1868 a Isidora Zegers.
} 
ningún familiar parece tener partitura alguna. Al menos, esta es la teoría que siempre se ha manejado a nivel familiar y la explicación más plausible por la desaparición de su música. El mismo Ried, en una carta a Isidora Zegers de octubre de 1868 le señala que hace "tres años calculaba yo que por este tiempo pudiera haberme retirado del negocio activo, no con una fortuna, pero con lo suficiente para poder haber vivido modestamente en mi patria, y haber tenido tiempo para producir mis composiciones. Con la ruina que me causó el bombardeo mis esperanzas han desaparecido." Sin embargo, un mes más tarde le escribe en los siguientes términos a su amiga respecto a la situación en el Teatro Victoria, en Valparaíso y el Teatro Nacional, en Santiago: "Si el empresario quisiera combinar sus esfuerzos con los mios, me comprometeria hacer de estos dos teatros los primeros de las Américas en mui poco tiempo. Tengo tantas composiciones preparadas para mi proyectado viaje a Europa, que pudiera darle una opera nueva cada seis u ocho meses por un largo tiempo." 41

Creo que el bombardeo, antes que una destrucción material, fue una desmoralización completa para Ried. Su informe del mismo, redactado en inglés y en poder de la familia, es un texto dolido y penetrante "con el objetivo de trazar la imagen de una ciudad ardiendo, con todos sus horrores concomitantes, como solo las acciones deshumanizadas pueden perpetrar, cuando siguen ciegamente sus propias pasiones, o el comando de monstruos con corona". En el texto no solo ataca a España, sino también a Perú, Estados Unidos e Inglaterra, por no evitar tal catástrofe y quedarse de brazos cruzados. Incluso a los chilenos, a los que se refiere en tercera persona, refrenda en el texto, pues "si se vieron insultados o heridos, tenían el derecho a resistir, pero debieron haber primero recordado, que en ningún caso se encontraban preparados para una guerra”. Para Ried, emocionalmente, la pérdida de sus pertenencias se sumó a un acto vil contra una ciudad indefensa, alistándose para una invasión. “¡No hay registro, en la historia de nuestros tiempos modernos, de un acto más barbárico, más cobarde o más execrable que el bombardeo de Valparaíso!". ${ }^{42}$

Como él mismo señala, después de esta fecha toda esperanza de montar una obra en Chile -esperanza de largos años- quedaba inevitablemente postergada. Sólo un regreso a Europa, un reencuentro necesario, podía ser el lugar para mostrar todo ese producto artístico de años; quizás como los aventureros que volvían a Europa para poder publicar sus memorias de viaje, su encuentro con el otro. Este viaje a Europa puede haber nacido de una frustración, también definitiva, con Chile. Por estos años declaró también que Chile era sólo un lugar para "mantener nuestro idioma incólume, nuestra nacionalidad sin mezcla, cuidando nuestro sagrado destino germánico de toda influencia". ${ }^{43}$ La drástica chilenidad de los primeros años había retornado a un germanismo marcado, en particular reflejado por la creación de Teutonia como drama y obra cumbre, ausente ya de toda música. Claramente, la muerte frustró su viaje, su creación y su reencuentro alemán, enterrando su música en el olvido chileno,

Pero en esta separación Chile-Alemania también hay un retorno. Si observamos los extractos sobrevivientes de las obras, en principio la Telésfora no es un polo

\footnotetext{
${ }^{41}$ Cartas del 11 de octubre y 5 de noviembre de 1868 a Isidora Zegers.

${ }^{42}$ Informe del bombardeo del 31 de marzo de 1866, incluyendo el aviso del almirante español el 27 del mismo mes y fotografías. Archivo Ana María Ried Undurraga. Traducción propia.

${ }^{43}$ Izquierdo, 2008:38; referido en un documento sobre la Escuela Alemana de Valdivia.
} 
opuesto a Teutonia. Sería un pensamiento casi obvio si nos quedamos en sus títulos, pero ambas son en realidad dos caras de una misma moneda. La obra de Ried es la de un romántico europeo que optó por darle realidad al concepto de "wandern". Las ideas, los ideales dirían Liszt y Schiller, permanecen; los lugares y las personas son las que se vuelven superficiales. El viaje, por lo tanto, es necesario. De alguna manera, el concepto de libertad sobresale a los límites políticos, entrando en una esfera propia de su generación y las revoluciones liberales burguesas, de las que era fiel adepto. Como señalaba el historiador W.T. Krug en 1823, el deseo por la libertad para su generación era la conclusión natural del "impulso evolutivo de la humanidad, que no es más que la lucha por la liberación de las limitaciones de tiempo y espacio" ${ }^{\text {"4 }}$. Es por esta razón que la libertad tiende un puente hacia la naturaleza y ese "hombre natural" que Ried cree encontrar en el mapuche de la frontera. Ese universo libre se presenta finalmente al espíritu romántico como un "campo unitario". Es el único que puede eternamente reflejar a la persona y, finalmente, cambiar éticamente al hombre burgués, en un encuentro con el otro en el que ambos desaparezcan en su propia individualidad y, por consiguiente, se crucen en una ansiada libertad social, cultural, nacional e individual.

La Telésfora, finalmente, puede quizás ser considerada la primera ópera chilena, y espero no contradecirme en esto. Las fiestas públicas y privadas, y la teatralidad religiosa y profana fueron esenciales para educar cívica y culturalmente a los chilenos antes de ser, efectivamente, chilenos. Por su parte la ópera se transforma, durante el siglo XIX, en un espacio cada vez más institucionalizado para nuestra naciente clase burguesa, animada por las inmigraciones. Es la propia oligarquía chilena la que recibe de brazos abiertos al inmigrante para usarlo como referente, dejándolo vivir entre nosotros como espejo de fantasía, hasta que reflejo y objeto se vuelven un solo elemento o se rechazan desde polos opuestos. La Telésfora es, justamente, el resultado artístico de este proceso y también un gesto, si no de poder, al menos de pesadez cultural. Ried creyó que podía entregar a Chile una obra que sirviera, al menos entre sus clases dirigentes, para afianzar los valores que como autor creía necesarios para una nueva y republicana sociedad burguesa. Sin embargo, el rechazo con que se encontró, no pudo sino convencerlo de que tal gesto podría ser inútil. No se observa en Chile al inmigrante para aprender en diálogo, sino para imitarlo y, por lo tanto, la llamada pública de un viajero a volver la vista a nuestros propios problemas era un asunto, sin duda, irrelevante para nuestra elite.

La Telésfora estaba llamada a permanecer muda, porque Chile no era todavía un país que necesitara una institucionalización de sus propias artes representativas. No existiendo ni una burguesía comerciante con un poder relevante en la discusión política ni una aristocracia con necesidad de autovalidación pública, una ópera "nacional" se vuelve innecesaria, puesto que el problema de la identidad no es aún relevante para las clases regentes del destino nacional. Las obras de Ried no sobrevivieron para ser hoy revividas, cuando las necesitamos como sociedad y tenemos el dinero para poder

\footnotetext{
${ }^{44}$ Citado por Meyer, 2003:16. La libertad es "the evolutionary drive in humanity, which is only the struggle for liberation from limitations of time and place".
} 
montarlas como hubiese querido el autor. Solo ahora, en tiempos del bicentenario, podríamos habernos visto en ese espejo de Ried para encontrar que, finalmente, Chile y su(s) teatros están listos para generar una tradición de creación operística propia que, probablemente, estaría ya tan desfasada de su momento histórico que sólo podría nacer y morir en un mismo gesto.

\section{BIBLIOGRAFÍA}

Aylwin, Patricio

2008 Informe de la Comisión Verdad Histórica y Nuevo Trato con los Pueblos Indígenas. En http://biblioteca.serindigena.org/libros_digitales/cvhynt/

Revisado el 12/10/2010.

Castillo, Gabriel

1998 "Epistemología y construcción identitaria en el relato musicológico americano", RMCh, LIII/190 (julio-diciembre), pp. 15-35.

Claro Valdés, Samuel

1973 Historia de la música en Chile. Santiago: Editorial Orbe.

FonCK, Franz

ca 1900 Dr. Aquinas Ried Leben und Werke: Mit einem Lebensbild von Franz Fonck und zahlreichen Bildern und Zeichnungen nach Originalen aus dem Nachlass von Dr. Aquinas Ried. Santiago: Imprenta del Archivo Científico de Chile.

GerstärCKER, Friedrich

1856 Gestärckers Travels, Translated from the German. Londres : T Nelson and Sons.

GuARDA, Gabriel

2001 Nueva historia de Valdivia: 1552 - 1952. Santiago: Ediciones Pontificia Universidad Católica de Chile.

Irurozqui, Marta y Leticia Reina

1997 La reindianización de América, siglo XIX. Buenos Aires: Editorial Siglo XXI.

IZQUIERdo, José MANuel

2008 Cuando el río suena: Una historia de la música en Valdivia, 1840-1970. Valdivia: Autoedición con Fondos CONARTE.

Meyer, STEPHEN

2003 Carl Maria von Weber and the Search for a German Opera. Bloomington: Indiana University Press.

Pereira Salas, Eugenio

1941 Los orígenes del arte musical en Chile. Santiago: Imprenta Universitaria.

1957 Historia de la música en Chile (1850-1900). Santiago: Publicaciones de la Universidad de Chile. 
Pinto, Julio y Gabriel Salazar

1999 Historia contemporánea de Chile. Volumen II. Santiago: Lom Editores.

Ried, Aquinas

1847 La Telésfora. Ópera heroica en tres actos. Libreto. Valparaíso: Imprenta El Mercurio.

2005 Diario de viaje al Lago Llanquihue (1847). Incompleto. Santiago: edición privada de Ana María Ried, 2005.

Treutler, Paul

1953 Andanzas de un alemán en Chile. Santiago: Editorial del Pacífico Chile. La edición original fue publicada el año 1882 .

Sanhueza, Carlos

2006 Chilenos en Alemania y alemanes en Chile. Viaje y nación en el siglo XIX. Santiago: Lom Editores.

\section{Archivos}

- $\quad$ Archivo Emilio Held Winkler.

- $\quad$ Archivo privado Ana María Ried de Undurraga.

- $\quad$ Biblioteca Nacional de Chile

- $\quad$ Museo Histórico y Antropológico de la Universidad Austral de Chile

- $\quad$ Las cartas de Isidora Zegers se encuentran en un álbum privado que pertenecía a Eugenio Pereira Salas y que actualmente se encuentra en el Archivo Central Andrés Bello de la Universidad de Chile. Mis transcripciones fueron basadas en la copia digital realizada por Rodrigo Torres, a quien le agradezco especialmente. 